\title{
Adoção tardia por casal divorciado e com filhos biológicos: novos contextos \\ para a parentalidade
}

\author{
Late adoption by a divorced couple \\ with biological children: New \\ contexts for parenting
}

\author{
Livia Kusumi OTUKA \\ Fabio SCORSOLINI-COMIN ${ }^{2}$ \\ Manoel Antônio dos SANTOS
}

\begin{abstract}
Resumo
O objetivo deste estudo de caso é discutir a experiência de um casal divorciado, com filhos biológicos, que realizou uma adoção tardia. Os dados foram coletados por meio de entrevista individual semiestruturada e analisados mediante o referencial teórico da psicanálise winnicottiana. Os resultados mostraram que, após três anos divorciados, os participantes adotaram um adolescente, destacando como motivação o altruísmo. Em termos do amadurecimento emocional dos membros do casal divorciado, nota-se que eles renovaram o bom vínculo preexistente não apenas mediante o exercício da parentalidade adotiva, mas também pelo "desejo de ajudar" o adolescente por meio de sua inserção em um núcleo familiar. Nas falas dos pais, pôde-se perceber que a noção de família transcende a ideia de um simples arranjo nuclear tradicional constituído em torno do casal, uma vez que a conjugalidade não foi mencionada como condição para a adoção. Em contrapartida, a conjugalidade foi valorizada como condição para o nascimento do primeiro filho biológico, denotando que são atribuídas diferentes significações à parentalidade biológica e adotiva.
\end{abstract}

Unitermos: Adoção tardia; Parentalidade; Psicanálise; Relações conjugais.

\footnotetext{
Abstract

The aim of this case study is to discuss the experience of a divorced couple with biological children, who made a late adoption. Data were collected through semi-structured interviews and analyzed through the theoretical framework of Winnicott's psychoanalysis. The results

$\operatorname{coth}$

1 Ministério Público do Estado de São Paulo. Bauru, SP, Brasil.

2 Universidade Federal do Triângulo Mineiro, Departamento de Psicologia. Uberaba, MG, Brasil.

3 Universidade de São Paulo, Faculdade de Filosofia, Ciências e Letras de Ribeirão Preto, Departamento de Psicologia. Av. Bandeirantes, 3900, 14040-901, Ribeirão Preto, SP, Brasil. Correspondência para/Correspondence to: M.A. SANTOS. E-mail: <masantos@ffclrp.usp.br>.

Artigo elaborado a partir do projeto de pesquisa de L.K. OTUKA, intitulado "A vivência da adoção por famílias com filhos biológicos", Processo FAPESP no 2007/59106-1.

Apoio: Fundação de Amparo à Pesquisa do Estado de São Paulo e Conselho Nacional de Desenvolvimento Científico e Tecnológico.
} 
showed that, three years after the divorce, the participants adopted an adolescent, highlighting altruism as their motivation. In terms of the emotional maturation of the couple, it was noted that they renewed the preexisting strong relationship through the exercise of adoptive parenthood and the "desire to help" the adolescent through his inclusion in a nuclear family. In the statements of the parents, it could be seen that the notion of family transcends the idea of a simple traditional nuclear arrangement constituted around the couple, since conjugality was not mentioned as a condition that effected the adoption. In contrast, conjugality was valued as a condition in the birth of their first biological child, showing that different meanings are attributed to biological and adoptive parenting.

Uniterms: Late adoption; Parenting; Psychoanalysis; Marital relations.

A adoção é uma das formas de parentalidade não biológica regulamentadas pelo Estado, geralmente utilizada por casais que enfrentam uma condição de infertilidade. Na psicanálise amparada nos estudos de Winnicott (1945/1993; 1953/1997a; 1965/1997b), a adoção pode ser compreendida por meio de duas vertentes: (1) a dos problemas relacionados à situação da adoção, que não geram necessariamente ansiedade, visto que, se o processo transcorre bem, caracteriza uma história comum, com contratempos e perturbações que fazem parte de qualquer itinerário humano; (2) a das complicações resultantes do manejo inadequado do bebê, da criança ou do adolescente antes da adoção, o que envolve não apenas questões clínicas como também sociais e legais, incluindo a segurança jurídica na passagem da criança de uma família para outra (Ghesti-Galvão, 2008).

Nesse sentido, é fundamental que a experiência de adoção possa se dar em um processo de estabilidade que pressupõe algumas linhas de continuidade do novo lar, de modo a assegurar as condições de holding necessárias para sustentar o desenvolvimento saudável da criança. A adoção será um processo positivo para a criança ou o adolescente se, efetivamente, a nova família puder se sustentar como suficientemente boa, ou seja, se conseguir se identificar com as necessidades do novo ser inserido no seio familiar - lembrando que o adotado, muitas vezes, passou pelas vicissitudes de anos de institucionalização -, criando um ambiente seguro e capaz de prover suas necessidades emocionais (lyama \& Gomes 2005; Otuka, 2009).

Ao considerar o panorama da literatura científica, nota-se que pesquisas têm investigado as motivações para a adoção, quer seja em famílias constituídas apenas pela parentalidade adotiva, quer seja pelos arranjos ditos mistos, ou seja, compostos por laços consanguíneos e também adotivos (Andrei, 2001; Carter \& McGoldrick, 1995; Cerveny \& Berthoud, 1997; Costa, 2005; Cúneo et al.
2007; Diniz, 1993; Ebrahim, 2001; Ghesti-Galvão, 2008; Levinzon, 2004; Levy \& Féres-Carneiro, 2001; Otuka, Scorsolini-Comin \& Santos, 2009, 2010, 2012; Rosa, 2008; Sarti, 1996; Schettini, Amazonas \& Dias, 2006). Alguns estudos têm focado a questão da adoção tardia, ainda considerada não tradicional no contexto brasileiro (Costa \& Rossetti-Ferreira, 2007; Sólon, 2009; Vargas, 1998). Outras pesquisas têm se dedicado à investigação da construção da parentalidade adotiva (Santos, Raspantini, Silva \& Escrivão, 2003), do preparo emocional dos pretendentes à adoção (Scorsolini-Comin \& Santos, 2008) e do atendimento psicológico/psicanalítico a pais de crianças adotivas (Gomes \& lyama, 2001).

Embora a investigação dos arranjos mistos tenha se mostrado relevante nas últimas décadas (Mariano \& Rossetti-Ferreira, 2008) em função da abertura das famílias para uma gama de possibilidades de estruturação que já têm sido contempladas na nova lei da adoção (Brasil, 2009), ainda predomina a visão que entende a adoção apenas como uma opção para os casais inférteis, e não como uma escolha em termos de parentalidade, como no caso da adoção por casais homossexuais (Uziel, 2007). Ainda mais escassos são os estudos que envolvem processos de adoção conjunta - aquela realizada por um homem e uma mulher -, quando os membros do casal não mais vivem em situação conjugal.

A partir do exposto, o objetivo deste estudo é discutir a experiência de um casal divorciado e com filhos biológicos que, após a separação, realizou a adoção de um filho adolescente, e buscar compreender suas motivações e as vicissitudes enfrentadas no decurso desse processo.

\section{Método}

Este estudo descritivo, exploratório e transversal, desenvolvido sob o enfoque de pesquisa qualitativa, constitui um recorte de um projeto mais amplo, que 
teve como objetivo investigar as motivações para a adoção em casais que já haviam tido filhos biológicos. Nesse recorte privilegiamos um dos casais investigados devido à situação singular que apresentava, visto que os pais adotaram um adolescente - fato por si só incomum no contexto brasileiro -, quando já haviam dissolvido a sociedade conjugal, mantendo, contudo, seus papéis sociais de cuidadores parentais.

Para o alcance dos objetivos propostos, optou-se pela estratégia metodológica do estudo de caso (Peres \& Santos, 2005), entendendo-se que essa escolha é adequada porque permite uma análise aprofundada de um caso que se distancia das situações habitualmente encontradas no cenário da adoção. Nesse tipo de enfoque metodológico, existe uma limitação na extensão da casuística investigada, entretanto o estudo de caso permite uma abordagem em profundidade do fenômeno focalizado, com ênfase na constituição da subjetividade humana.

\section{Participantes}

O estudo contou com a participação de um casal - Elaine (34 anos) e Severino (39 anos) -, que efetivou a adoção de um adolescente, Washington (17 anos). Como critério para a inclusão dos participantes foi definido que o casal deveria ter pelo menos um filho biológico, nascido antes do processo de adoção, e estar cadastrado em um grupo de apoio à adoção de uma cidade do interior paulista. Elaine e Severino tiveram três filhos biológicos antes da adoção de Washington: Nilmar, 12 anos; Kleiton, 10 anos; e Edson, 6 anos. Para preservar o anonimato dos participantes, os nomes próprios utilizados neste estudo são fictícios.

\section{Instrumentos}

Para a coleta de dados foram utilizados os seguintes instrumentos: (a) questionário de caracterização sociodemográfica, constituído por questões relativas ao sexo e à idade de cada membro da família, nível de escolaridade, profissão/ocupação, estado civil, religião e renda familiar; (b) roteiro de entrevista semiestruturada, delineado especialmente para atender aos objetivos do presente estudo, com base em investigações similares desenvolvidas anteriormente pelo grupo de pesquisa
(Otuka, 2009; Pereira \& Santos, 1998). Esse roteiro era composto por questões abertas que exploravam a experiência do casal adotante em relação ao processo de adoção.

\section{Procedimentos}

A entrevista foi realizada com os pais adotivos na residência da mãe. Teve durações de 90 minutos, foi audiogravada e, posteriormente, transcritas na íntegra. O método empregado para o tratamento dos dados foi a análise de conteúdo temática (Triviños, 1987) e a interpretação apoiou-se no referencial psicanalítico de inspiração winnicottiana. Na tentativa de compreender a vivência dos pais adotivos, após a realização de várias releituras do material transcrito, foram identificadas unidades de significado e elaboradas categorias de análise.

Este estudo foi aprovado pelo comitê de ética em pesquisa da instituição de ensino superior (Protocolo n³18/2007-2007.1.918.59.6).

\section{Resultados}

Severino e Elaine se conheceram em uma quermesse e logo iniciaram um relacionamento afetivo. Namoraram durante três ou quatro meses e, após esse período de namoro, decidiram morar juntos; pouco tempo depois se casaram, permanecendo unidos por 14 anos. Em relação à parentalidade, Elaine relata que sempre tivera o desejo de ter filhos. Para Sarti (1996) e Levy e Féres-Carneiro (2001), a ideia de formar uma família está sempre associada ao desejo de ter filhos e, assim, perpetuar a tradição familiar. Dessa forma, a família tradicional formar-se-ia a partir de três elementos-chave, a saber: o casamento entre um homem e uma mulher, a casa e a presença dos filhos. Os participantes em questão associam claramente o desejo de exercer a parentalidade à união conjugal, como se a construção da família fosse completar-se a partir da chegada dos filhos. É importante ressaltar, entretanto, que, no início de sua vida em comum, o casal viu-se obrigado a enfrentar a postergação da maternidade/paternidade devido à impossibilidade de gerar filhos biológicos.

A condição de infertilidade ou esterilidade, segundo a literatura, é apontada como um dos prin- 
cipais motivos relatados por casais que optam pela adoção. Levando em consideração as diferentes posições subjetivas que homens e mulheres ocupam no conflito edípico, segundo a teoria psicanalítica, a dinâmica inconsciente quanto ao desejo de ter filhos é diferente para ambos. Para a mulher, uma criança ocupará um lugar simbólico que se encontrava vazio no seu imaginário, preenchendo, dessa maneira, uma falta estrutural em sua subjetividade. Quanto ao homem, por sua vez, a procriação é a materialização de sua fertilidade, que confirmaria sua virilidade aos olhos do outro. Do ponto de vista da cultura e da construção dos papéis de gênero, a gravidez feminina confirma a potência masculina; o homem, nesse sentido, sente-se cobrado a justificar sua masculinidade (Schettini et al., 2006). Desse modo, trazer um filho ao mundo tem função estruturante, ainda que diversa, no psiquismo do homem e da mulher.

Severino e Elaine se submeteram a tratamento médico e, após cinco anos de sucessivas tentativas, relatam, com evidente satisfação, que foram capazes de gerar uma criança. Em relação à parentalidade biológica, é possível apreender a satisfação com os aspectos biológicos da parentalidade. Severino relata que a maior alegria vivenciada foi o dia do nascimento do primeiro filho.

E de repente ver aquela criança minha, do meu lado, tudo... Aquilo foi uma experiência mais forte... . Foi uma alegria muito grande (Severino).

No discurso paterno, é possível inferir o impacto do nascimento do filho, especialmente do sexo masculino, para o homem. Pode-se pensar que, com o nascimento do filho, Severino foi capaz de restaurar sua injúria narcísica ancorada em uma falha física e superar seu sentimento de impotência suscitado pelo diagnóstico de infertilidade. Essa experiência emocional marcante foi acompanhada de um sentimento de completude e contentamento, pois desmentia a sentença médica e lhe devolvia o poder de comprovar sua virilidade. A gravidez de Elaine, nesse sentido, apareceria como a confirmação de sua potência, evidência cabal e insuspeita de sua própria masculinidade.

Elaine, por sua vez, ressalta sua satisfação com a gravidez e o júbilo vivenciado no momento em que 92 soube que estava esperando um filho. A sensação de plenitude, produzida pela confirmação há tanto tempo aguardada, parece exercer uma função reparadora:

Acho que no momento que eu fiquei sabendo que eu tava
grávida, pra mim já... Já foi assim, é, a maior alegria, né,
pra quem não poderia ter nada... Então, pra mim, acho
que no momento assim que eu fiquei sabendo o
resultado, assim... Acho que foi a maior alegria mesmo...
Edepois que nasceu também, né? (Elaine).

Dessa forma, na perspectiva de Elaine, vale ressaltar que a alegria vivenciada com a gravidez aparece, conforme mencionado por Schettini et al. (2006), como o preenchimento de uma falta: o filho que não poderia gerar estava finalmente por vir, para ocupar um lugar vazio em seu imaginário. A sensação de júbilo marcou a transição para a parentalidade, deslocando-a da posição de quem não poderia ter nada. Desse modo, pode-se pensar no papel que o filho biológico desempenhou na vida do casal, permitindo-lhe passar do sonho impossível à realidade possível, "da maternidade impossível ao possível da filiação" adotiva (Levy \& FéresCarneiro, 2001), da impotência à potência, do vazio à plenitude. Ser mãe representou tanto a possibilidade de ser como de ter "pra quem não poderia ter nada", como relatou Elaine.

Elaine e Severino relatam, ainda, a satisfação que experimentam com o amor dos filhos, colocando em um mesmo patamar de importância os três filhos biológicos que tiveram no período em que foram casados e o filho que adotaram quando já estavam separados. A participante afirma que, apesar de ser uma mãe rígida, percebe que seus filhos a compreendem, apoiando-a nos momentos difíceis, com muito carinho e respeito. Para Cerveny e Berthoud (1997), embora as recompensas da transição de papéis de homem e mulher para os de pai e mãe sejam intensas, igualmente impactantes são as ansiedades, os conflitos e as angústias vivenciados, além do crescente sentimento de responsabilidade. Dessa forma, em relação às mudanças vivenciadas com a chegada dos filhos, os participantes descrevem que deram maior atenção às crianças do que à relação conjugal.

Ai.... Acho que mudou muita coisa, assim.... Porque agente viveu cinco anos sem filho, né... Eagente tinha mais tempo pra tá junto sempre, tinha mais tempo pra... . Pra sair e não precisava se preocupar nem nada, aí depois com a vinda dos filhos, não équalquer lugar que a gente poderia 
ir... Não, é, às vezes assim, a gente não poderia ficar tanto tempo mais sozinho, então (Elaine).

A chegada do primeiro filho pode ser considerada um momento de crise, um período temporário de desorganização do funcionamento de um sistema até então equilibrado, iniciado por circunstâncias que, transitoriamente, ultrapassam os recursos do sistema para adaptar-se tanto externa quanto internamente. A transição para a parentalidade requer tanto o ajustamento conjugal como emocional dos pais (Hernandes \& Hutz, 2009). Devido às questões que permeiam a transição para a parentalidade, o casal em questão precisou reorganizar-se em relação às expectativas, ao estilo de vida, ao relacionamento com amigos e parentes, sendo necessárias muitas negociações para se obter uma boa adaptação à nova situação (Cerveny \& Berthoud, 1997).

Ademais, Elaine e Severino fazem referência às dificuldades de aprendizagem do filho biológico, Nilmar, as quais parecem ser enfrentadas com afinco pela mãe. É interessante destacar a concepção de Winnicott (1965/1997b) a respeito do sintoma (no caso, a dificuldade escolar) como um sinal de esperança, como a procura da criança por pais suficientemente bons que possam auxiliá-la em suas dificuldades. Dessa forma, por meio do provimento de um ambiente suficientemente bom, capaz de atender às suas necessidades e fornecer-lhe suporte, a criança pode encontrar as condições favoráveis para que possa continuar a ser, a prosseguir em sua linha de desenvolvimento, que fora interrompida por alguma adversidade.

Decorridos 14 anos de casamento, Severino e Elaine concluíram que a relação conjugal tinha se desgastado e optaram pelo divórcio. Acreditam que, no início, foi um pouco difícil para os filhos aceitarem a separação, principalmente para Nilmar, muito apegado ao pai. Com o passar do tempo, entretanto, afirmam que as crianças assimilaram bem a decisão do casal, preferindo os pais separados e felizes, ao lado de seus novos parceiros (no momento da realização da entrevista, Elaine namorava Bruno havia 10 meses e Severino coabitava com Amélia por igual período). Ambos afirmaram que continuaram mantendo um relacionamento amigável e que os filhos mantêm boas relações com os respectivos companheiros. Após três anos divorciados, os participantes decidiram adotar Washington, que na época contava com 15 anos. Embora a lei faculte a adoção por um indivíduo solteiro ou separado, consideraram que seria melhor para o adotado que tivesse um pai e uma mãe adotivos. A respeito da construção da motivação para adotar, Elaine menciona seu desejo de ajudar o filho adotivo, podendo-se apreender, nessa fala, uma motivação da participante relacionada ao altruísmo.

Aúnica coisa assim que eu pensei, assim, é ajudar ele... E ajudar assim... é... que ele sentisse como éviver dentro de uma família... Nenhuma outra coisa assim de ter alguma coisa em volta, você diz, assim, não? Ter só o carinho de filho dele mesmo, né? (Elaine).

Para Levinzon (2004), a ideia de que há muitas crianças necessitadas e que adotá-las seria uma maneira de ajudá-las, fazendo um bem à sociedade, constitui uma das razões relatadas por pais para explicar sua opção pela adoção. O desejo de ajudar e de amar uma criança, entretanto, por si só, não é razão suficiente para a adoção. O vínculo parental, assim, não pode ser estabelecido unicamente em função de desejos altruístas ou como uma forma de salvação da criança, posto que a filiação envolve vivenciar emoções diversas e muitas vezes intensas e ambivalentes, que precisam ser sustentadas durante longos períodos de tempo. Em contrapartida, as famílias se encontram sempre em busca de integração. Para que o processo ocorra de forma harmoniosa, é essencial que os pais tenham claro que desejam um filho e que não estão apenas fazendo o bem a ele. É importante que a criança adotiva sinta que tem um lugar escolhido dentro de sua família (lyama \& Gomes, 2005; Levy \& Féres-Carneiro, 2001).

Ademais, vale ressaltar que, se os pais são vistos como benfeitores, aos quais se deve gratidão, o filho fica impedido de vivenciar e exprimir sua agressividade, competição e rivalidade (Diniz, 1993). Elaine e Severino descrevem Washington como uma pessoa "sem defeitos" nem maldade no coração, muito boa, obediente e responsável. Talvez, nesse contexto, os pais estejam ocupando um papel muito idealizado no imaginário do filho adotivo, o que pode impedi-lo de dar vazão a seus sentimentos hostis e agressivos. Precisaria, assim, tornar-se um filho "perfeito" para se sentir incondicionalmente aceito e amado por seus pais ideais, percebidos como grandes benfeitores.

É possível que o adolescente esteja se relacionando dessa forma com os pais adotivos, reagindo 
às suas expectativas e adequando-se às necessidades do ambiente em vez de permitir que suas próprias necessidades sejam satisfeitas pelo meio. Para Winnicott (1965/1997b), a criança que cresceu em um ambiente de privação da gratificação de suas necessidades básicas usualmente pode vivenciar sentimentos perturbadores em função de seu passado marcado por experiências traumáticas. Entretanto, quando a criança mostra-se capaz de beneficiar-se de um ambiente suficientemente bom e seguro, ela dá indícios de melhora. "Menos doente", a criança reage com fúria ao seu estado de carência emocional. Winnicott (1965/1997b) explicita que há na criança um ódio dirigido contra o mundo. A saúde emocional, assim, só pode ser alcançada quando esse ódio pode ser sentido, tendo condições de ser reconhecido e expresso no ambiente.

Em uma das situações narradas por Elaine em sua entrevista, é possível perceber que Washington, provavelmente, procurava testar o amor dos pais adotivos e seu sentimento de pertença à família, agindo com ódio em relação às normas e aos valores familiares. Além disso, convém lembrar que a transgressão é parte do repertório de comportamento dos adolescentes que buscam se autoafirmar muitas vezes por meio do oposicionismo. Elaine apresentou uma postura firme, mostrando ao filho que sobreviveria a seus "ataques" às regras familiares instituídas, mas que seus atos não passariam despercebidos ou sem consequência. Desse modo, ao demonstrar ser capaz de fornecer-lhe holding, ela possibilitou que Washington se assegurasse quanto à confiabilidade e à estabilidade de seu novo ambiente familiar.

Seria importante, ainda, questionar se Washington teve espaço, em outros momentos, para expressar seu ódio e sua agressividade contra o mundo. Caso Elaine e Severino estejam sendo vistos pelo filho como "pais salvadores", como poderia demonstrar ostensivamente sentimentos hostis em relação a eles e ao ambiente que o circunda? Que possíveis consequências para seu desenvolvimento poderia ter uma repressão maciça de tais sentimentos e comportamentos hostis? Segundo a teoria winnicottiana, que considera que o amor não existe sem o ódio, a provocação visa a gerar o ódio, em uma tentativa da criança de sentir-se amada, de solidificar sua sensação de pertencimento. Para onde, na 94 família em questão, estaria dirigido o ódio de Washington?
É importante ressaltar que, em sua fala, Elaine se mostra desejosa de receber o "carinho de filho" de Washington, o que parece indicar que o rapaz, no momento da adoção, ocupava um lugar simbólico já devidamente instituído na família que o receberia. O casal ressalta, em toda a entrevista, as alegrias vivenciadas com a chegada do adolescente à família, parecendo haver, dessa forma, um entrelaçamento de desejos: o desejo do filho adotivo de ter pais e o dos pais adotivos de terem um filho (Andrei, 2001). Assim, ainda que, possivelmente, Severino e Elaine estejam sendo idealizados como pais perfeitos, é essencial destacar que o desejo pelo filho adotivo e sua aparente disposição para exercer a parentalidade, constituindo um ambiente suficientemente bom, figuram como fatores positivos para o relacionamento entre os protagonistas da adoção. Além disso, deve-se tomar em consideração a possível gratidão de Washington pelo fato de ter sido contemplado com uma família em uma idade em que dificilmente o indivíduo institucionalizado logra a inserção familiar.

Quanto à reação dos filhos biológicos diante da decisão dos pais de adotar, o casal destacou o apoio recebido. Os participantes relatam que seus filhos biológicos insistiram para que os pais acolhessem Washington, uma vez que a família já mantinha contato com o adolescente institucionalizado. Elaine relata que sua sobrinha é madrinha do filho adotivo e que, por essa razão, o rapaz visitava sua casa em alguns finais de semana, quando se afastava do abrigo.

É, e eles ficavam muito preocupados de ele ficar com 18 anos e não poder... Não ter uma casa pra morar, não ter uma família, não ter ninguém, ficar na rua... . Aío Nilmar perguntou: "E se fosse eu que tivesse assim, nessa situação?". Aíagenteficoupensando, aíeu chegueinele, né [refere-se ao ex-marido], porque nessa época ele tava passando por um pouco de dificuldade, então ele veio morar aqui e ele que dividia o quarto com os meninos... Daíeu conversei com ele, né, se ele poderia, se não tinha nenhum problema... Aíelefalou que não, queporelenão teria problema (Elaine).

Tratando das mudanças introduzidas pela parentalidade adotiva, Severino e Elaine relatam que, com a chegada de Washington, mais velho e maduro que os filhos biológicos, aprenderam a respeitar um pouco mais as vontades das crianças. Tal atitude, mais uma vez, parece condizente com o modo peculiar de funciona- 
mento da família em questão, na qual o diálogo e o respeito às diferentes vozes figuram como valores fortemente enaltecidos e cultivados.

Então, às vezes, eu compreendi muito esta parte assim, que nem... que a gente tem que aprender a respeitar os filhos da gente... . Então, pra mim, ele trouxe isso, porque... . Respeitar a vontade deles também, embora a gente já respeitasse, mas em outros termos... . Mas aífez euentender que muitas coisas a gente tem que aprender a respeitar, não éporque éfilho da gente, que nasceu da gente, que a gente tem que tratar de qualquer maneira. Também tem que aprender a abrir e aceitar a vontade deles também, tentar entender um pouquinho eles (Elaine).

A situação de Washington enquadra-se na categoria de adoção tardia, que é aquela que envolve crianças com mais de dois anos de idade. Mas há uma particularidade notável. No contexto brasileiro, na maior parte dos casos, apenas as crianças de até três anos conseguem colocação em famílias substitutas, devido a uma crença culturalmente difundida de que há grande dificuldade em educar crianças maiores (Sólon, 2009). Acredita-se que dificilmente um indivíduo adotado tardiamente aceitaria as normas estabelecidas em sua nova casa, por estar com sua personalidade e formação social em estádio avançado. Os casais, portanto, adotariam bebês para conseguirem uma maior adaptação entre pais e filhos e uma adequada socialização, assegurando que as crianças atenderiam de maneira mais dócil aos desejos e expectativas da família adotante (Ebrahim, 2001). Washington, nesse sentido, é um caso exemplar que contribui para desmitificar tal crença arraigada no imaginário coletivo. Apesar das dificuldades, seus pais acreditam que o rapaz foi capaz de "entrar no ritmo da família", entender as sutilezas de seu funcionamento e reconhecer seu sistema de valores, superando facilmente as vicissitudes da etapa inicial de adaptação.

Ademais, Elaine revela que sofre com o preconceito de alguns de seus colegas em relação à adoção. Explica que diversas pessoas acreditam que o filho mais velho foi adotado para servir como empregado de seus filhos biológicos mais novos. Essa crença não é totalmente desprovida de consistência. Por vezes, jovens adotados passam a ser responsáveis por tarefas subalternas nas famílias que os acolhem, encontrando-se em uma condição de semiempregados. Porém, casos excepcionais não deveriam justificar a disseminação do preconceito. Elaine irrita-se com esse tipo de incompreensão em relação às reais motivações que a levaram a adotar o adolescente, mostrando-se ressentida com aqueles que a questionam e que, de certo modo, tentam invalidar seus esforços.

Eeu falei: "Eu tenho queir embora, porque o Nilmarnão tá bem, tudo..." Então ela disse assim: "Uai, e o seu filho mais velho?". Eu falei: "O Washington?". "É, por que que o Washington não leva ele no médico?". Falei: "Porque o Washington não émãe, o Washington nãoépai dele...". Então ela disse: "Então porquequevocêadotou ele?" Falei: "Eu adotei ele pra ele ser meu filho, não pra ele ser empregado dos meus filhos..." .... Então eu acho que, às vezes, as pessoas veem que, se você adotou uma pessoa, vocêtá fazendo uma caridade, ou você pegou a criança pra ser feita de empregada. Mas não é assim. Se você adotou, vocêtem que adotare tratarcom amor, carinho e respeito igual os outros filhos (Elaine).

Em relação ao passado do filho adotivo, Severino e Elaine esclarecem que Washington viveu em um abrigo e que visitava a família adotiva nos finais de semana, antes do processo de adoção. A partir do relato dos participantes, é importante ressaltar a existência de contato do casal com a família biológica de Washington. Elaine e Severino afirmam que o filho tem dois irmãos biológicos, que ainda vivem no abrigo e que visitam, quinzenalmente, as novas famílias de Elaine e Severino, passando, alternadamente, os finais de semana na casa de um dos pais adotivos. É interessante destacar que Elaine e Severino relatam o desejo de também adotar os irmãos de Washington, caso tivessem melhores condições financeiras. Desse modo, nota-se uma extraordinária disponibilidade emocional de ambos para acolher o outro e oferecer-lhe um lugar de pertença.

Ai, a minha intenção, assim, de verdade, era poder ajudar
o irmão e a irmã do Washington. Assim, sabe, tirar eles do
abrigo, assim, eu acho que pra mim, eu ficaria muito mais
feliz assim, porque é muito ruim saber que eu ajudei elee
não posso ajudar mais os dois. Pra mim, acho que se
tornaria muito mais feliz, porque... é... eles brigam, o
Washington, a irmã e o irmão, mas quando eles estão
juntos, é muito bom, sabe, aquela alegria, aquela coisa
gostosa de irmão mesmo, assim (Elaine).

Parece haver, nesse sentido, uma relação duradoura de afeto e de cuidados da parte do casal em relação aos irmãos consanguíneos do filho adotivo. Seve- 
rino e Elaine ressaltam, ainda, o passado silenciado por Washington, afirmando que, no início, o rapaz até conversava sobre sua história pregressa, porém, com o passar do tempo, parece ter deixado o assunto de lado, não mais se mostrando disposto a falar de sua mãe biológica ou do que se passou com ela. Este comportamento pode ter sido influenciado por algo que seus pais adotivos Ihe disseram a respeito do passado, de que não poderiam modificá-lo, mas que seu futuro poderia ser diferente. Assim, percebe-se um enfoque no futuro em detrimento de um recontar sobre o passado. Para Levinzon (2004), por vezes, a criança mostra-se receosa em conversar com os pais a respeito da adoção por imaginar que eles se ressentiriam por isso, ou que pensariam que ela poderia estar rejeitando o novo lar.

Dessa forma, pode-se levantar a hipótese de que Washington prefira não conversar a respeito de seu passado por medo de magoar os pais adotivos, que poderiam sentir-se ameaçados ou rejeitados em sua função parental. Tal atitude parece condizente com a visão extremamente positiva que Elaine e Severino cultivam do filho adotivo: sendo um "bom rapaz", ele poderia desdobrar-se na tentativa constante de não desagradar os pais adotivos, possivelmente influenciado pelo temor de perda de seu amor. Nesse sentido, seu silêncio a respeito do passado pode figurar como uma busca pela valorização do relacionamento com os pais adotivos, em detrimento do vínculo com a família biológica.

Em relação ao relacionamento entre pais e filhos, o casal o descreve como muito bom, sem maiores dificuldades, embora permeado por alguns atritos. No que diz respeito às semelhanças e as diferenças entre os filhos biológicos e adotivo, Elaine e Severino procuram enfatizar a igualdade no relacionamento que estabelecem com eles. Nota-se uma negação explícita de qualquer diferença no modo de tratar cada filho, em razão de sua condição de biológico ou adotivo. Desse modo, a harmonia familiar mostra-se perfeitamente compatível com o convívio entre laços consaguíneos e socioafetivos.

A participante menciona o exemplo de uma colega do grupo de apoio para casais adotantes que eles frequentam que afirma que, independentemente da condição de ser biológico ou adotivo, é preciso saber 96 lidar com as dificuldades do filho.
O filho tá dando trabalho, então devolve! Aí ela falou assim: "A minha filha tá dando trabalho, saiu de dentro demim, como queeu vou pôr devolta?" Então ela sempre, o seu natural, como vocêvai pôr de volta? Não tem como, vocêtem que aturar ele. Então, do mesmo jeito quevocê tem que aturar ele, você tem que aturar o que você adotou também. Ele não pediu pra ser adotado, ele.... E acho que, às vezes, têm filhos naturais que às vezes fazem coisa pior com os pais do que outros que não foram, né? (Elaine).

Nessa fala, Elaine pontua o desejo dos pais de adotar ao dizer: "simplesmente a gente que teve a vontade". Segundo Winnicott (1953/1997a), a partir do provimento de um ambiente suficientemente bom, uma relação profunda pode ser construída por meio da adoção, na qual a criança adotiva se sinta seguramente sustentada e acolhida, como pertencendo à família que a recebeu (Gomes, 2006). Na família em questão, Elaine parece ter sido capaz de se constituir como uma mãe suficientemente boa, identificando as necessidades do filho adotivo de modo a lhe prover um holding adequado. Ademais, todo o ambiente familiar, incluindo Severino e os filhos biológicos do casal, parece figurar como um contexto positivo para o desenvolvimento de Washington, proporcionando que o adolescente se sinta parte integrante do círculo familiar, legitimado como filho e irmão pelo laço socioafetivo. Nesse sentido, é importante refletir o quanto os laços de sangue (biologia) não garantem a qualidade e a estabilidade do vínculo, que dependeriam, essencialmente, da forma como o laço foi construído e consolidado. No caso em apreço, também a situação marital do casal não é o esteio que assegura as condições de desenvolvimento dos filhos, sejam eles biológicos ou adotivos, mas sim o tipo de vínculo afetivo - respeitoso, amistoso, solidário -, que mantêm Severino e Elaine unidos em torno do projeto compartilhado de cuidar dos filhos. Esse casal, que não existe mais do ponto de vista formal, preservou - e até mesmo renovou e ampliou, por via da adoção -, o compromisso da parentalidade, o que atesta a vitalidade do vínculo que os mantém unidos, mesmo após o projeto de vida conjugal ter se dissolvido. Isso corrobora o pressuposto de que, nos casais que se separam, a durabilidade do projeto parental pode perfeitamente sobreviver à dissolução do vínculo conjugal.

Severino e Elaine explicam as possíveis singularidades existentes nos relacionamentos parentais que 
mantêm, tomando por base a diferença de idade entre os filhos. Dessa maneira, para os participantes, as diferenças existentes dizem respeito à faixa etária, e não à condição de ser biológico ou adotivo. Para Cúneo et al. (2007), o filho adotivo criado junto a um filho biológico no interior de uma mesma família pode gerar sentimentos ambivalentes e alguns temores. No caso em questão, parece haver um esforço por parte dos pais em negar possíveis diferenças entre os filhos biológicos e o adotivo. Tal achado pode estar relacionado a uma tentativa de combater o preconceito que envolve o contexto da adoção: os pais perceberiam e tratariam os filhos da mesma forma para que eles não se sentissem prejudicados ou menos amados em relação aos outros, evitando que a condição de adotivo ou biológico influenciasse os relacionamentos intrafamiliares e repercutisse negativamente na autoestima dos filhos. Dessa maneira, igualando-os - pelo menos no plano do discurso manifesto -, estariam tornando equivalentes o afeto, os cuidados e o amor dispensados a cada um deles. Pode-se concluir, assim, que o relacionamento entre pais e filhos, no presente caso, é marcado pela proximidade, senso de justiça e anseio igualitário.

A vidanão éum mar derosas, né? Às vezes tem um pouco de espinho, você pega uma roseira, tem espinho, você pega outra, tem espinho pra machucar a mão. Mas eu acho que quando vocêépai, a educação e a convivência vêm primeiro. Eisso traz muita felicidade e muita alegria. Com o diálogo, o respeito, às vezes uma briguinha aqui, uma briguinha ali, mas semprejuntos (Severino).

Severino e Elaine descrevem o relacionamento familiar como bastante positivo, permeado pela alegria e pelo amor, consubstanciados na expressão: "mas sempre juntos". Explicam que o relacionamento entre os irmãos é marcado por proximidade, relatando que, apesar de algumas brigas, eles se defendem entre si e não aceitam que outras pessoas externas à família lhes façam mal, o que demonstra um forte sentimento de união e solidariedade. Nesse contexto, os laços de lealdade fortalecem o sentimento de pertencimento. O lema de Severino - "mas semprejuntos" -, permeia as relações familiares, que prescindem da conjugalidade e da coabitação dos pais para se consolidarem de forma harmoniosa na convivência cotidiana.

Ademais, pode-se notar o discurso da normalidade presente nas falas de Severino e de Elaine. Em seus relatos, é possível apreender uma tentativa de naturalizar as relações que os filhos estabelecem entre si, tornando- -as iguais ou próximas às relações existentes entre irmãos biológicos. Segundo Costa e Rossetti-Ferreira (2007), algumas pessoas que buscam a adoção comumente estão tomadas por concepções de maternidade, paternidade e família que valorizam os vínculos consanguíneos e o modelo biológico de parentalidade. Esse ideal estaria ligado à concepção de que as relações biológicas seriam naturais e mais saudáveis, o que poderia explicar, assim, o desejo do casal de "normalizar"o relacionamento fraterno dos filhos. A atitude do casal, nesse sentido, pode estar relacionada com a tentativa de não fazer qualquer diferenciação entre os filhos. Parece haver um temor velado de que apontar singularidades no plano dos relacionamentos intrafamiliares, devido à sua condição de biológico ou adotivo, poderia denotar uma atitude preconceituosa e negativa em relação à adoção, de forma a valorizar os filhos biológicos em detrimento do adotivo.

Para Carter e McGoldrick (1995), com a transição para a parentalidade, a família se transforma em um grupo de três, o que a torna um sistema permanente. Assim, se um cônjuge sem filhos parte, não permanece nenhum sistema; entretanto, se uma pessoa deixa a nova díade do casal e do filho, o sistema sobrevive. Dessa maneira, pode-se notar que o enfoque dado pelo casal ao futuro dos filhos, ao seu estudo e ao seu sucesso profissional pressupõe a continuidade dos valores e crenças cultivados pelos pais. O sistema familiar, nesse contexto, permaneceria: o futuro estaria relacionado à continuidade dos projetos de vida dos filhos, à possibilidade de galgarem um degrau além daquele que seus pais alcançaram. Assim, o êxito dos filhos como seres adultos e autônomos poderia coroar o futuro idealizado por Elaine e Severino. Porém, esse ideal de continuidade bem-sucedida, contido nas representações sociais e culturais da parentalidade, não é mera reprodução do estabelecido, do establishment familiar, porque também supõe renovação e aprimoramento do legado intergeracional recebido. Nesse sentido, não se trata apenas de mera repetição de padrões legados às futuras gerações. A parentalidade, vivenciada em suas diversas possibilidades, também traduz um anseio de transformação dos conteúdos transmitidos por herança psíquica.

\section{Considerações Finais}

Em termos da história pregressa do filho adotivo, levando-se em conta a importância do desenvolvimento 
emocional primitivo na constituição do senso de existência do indivíduo, pode-se pensar que foi preciso que Washington se adaptasse ao ambiente no qual foi socializado (serviço de acolhimento institucional), posto que esse meio, possivelmente, não foi capaz de responder às suas necessidades de forma consistente. Dessa forma, é possível que o adolescente esteja se relacionando de modo análogo com os pais adotivos, reagindo e adequando-se às necessidades do ambiente, em vez de permitir que suas próprias necessidades sejam satisfeitas.

No que concerne ao desenvolvimento do casal divorciado, nota-se que eles mantêm seus vínculos não apenas pelo exercício da parentalidade adotiva, mas também pelo desejo de redimir o adolescente por meio da oferta de um lugar de pertença, ou seja, pela possibilidade de inseri-lo e sustentá-lo em uma família. Nas falas dos pais, pode-se perceber que a noção de convívio familiar transcende à ideia de um simples arranjo tradicional constituído em torno de um casal, uma vez que a conjugalidade não é mencionada como uma condição indispensável para a adoção, mas sim como um requisito para amparar o nascimento do primeiro filho biológico. No caso da experiência da adoção, julgam ser de igual importância, para favorecer o desenvolvimento dos filhos, assegurar tanto o exercício do papel materno como paterno, ainda que as figuras materna e paterna não estejam mais unidas pelos laços do matrimônio.

Podemos perceber, desse modo, uma sutil distinção entre os pré-requisitos familiares eleitos pelos participantes para a parentalidade biológica e para a adotiva. Isso pode ser interpretado do seguinte modo: como Elaine e Severino já estavam "ajudando o próximo", poderiam exercer esse altruísmo independentemente de sua situação conjugal, desde que mantivessem intactos os seus papéis de pai e mãe. Filhos adotivos precisariam de pais, assim como os biológicos, mas poderiam ser perfeitamente inseridos em um lar cujos pais tivessem se divorciado, desde que eles não tivessem se descomprometido de suas funções parentais.

Além disso, Severino e Elaine parecem se empenhar para que os filhos biológicos também possam seguir seu exemplo e cultivar uma atitude altruísta, preocupando-se com os outros e se esmerando em apoiá-los em suas dificuldades. Vale ressaltar que esse 98 altruísmo parece ser bastante valorizado na família em questão, evidenciando-se, por exemplo, na motivação alegada como determinante na tomada de decisão pela adoção. Pode-se problematizar se a escolha da parentalidade adotiva no casal em questão realmente passa apenas pelo anseio de ajudar um adolescente sem lar, pois parece advir, sobretudo, do desejo de continuar exercendo os papéis materno e paterno independentemente da manutenção ou da dissolução do laço conjugal. Antes de mais nada, ser pai e ser mãe parecem ser vividos como uma realização pessoal por ambos os ex-cônjuges, como oportunidade de oferecer ao outro e a si mesmos um contexto favorável ao enriquecimento humano e à conquista da maturidade emocional. Essa hipótese deve ser melhor investigada em estudos futuros, por meio de estratégias metodológicas mais robustas que permitam a generalização dos dados.

O presente estudo também permite evidenciar o quanto as concepções e os pensamentos oriundos do senso comum, que regulam o comportamento dos pais que adotam, necessitam ser conhecidos e esclarecidos de modo a assegurar condições de pleno desenvolvimento aos filhos adotivos.

\section{Referências}

Andrei, E. (2001). Adoção: mitos e preconceitos. In F. Freire (Org.), Abandono e adoção: contribuições para uma cultura da adoção III (pp.41-50). Curitiba: Terra dos Homens.

Brasil (2009, 4 de agosto). Lei n. 12.010, de 3 de agosto de 2009. Dispõe sobre adoção; altera as Leis no 8.069, de 13 de julho de 1990 - Estatuto da Criança e do Adolescente, 8.560, de 29 de dezembro de 1992; revoga dispositivos da Lei no 10.406, de 10 de janeiro de 2002 Código Civil, e da Consolidação das Leis do Trabalho CLT, aprovada pelo Decreto-Lei no 5.452, de $1^{\circ}$ de maio de 1943; e dá outras providências. Brasília. Diário Oficial da União, Seção 1.

Carter, B., \& McGoldrick, M. (1995). As mudanças no ciclo de vida familiar: uma estrutura para a terapia familiar. Porto Alegre: Artes Médicas.

Cerveny, C. M. O., \& Berthoud, C. M. E. (1997). Família e ciclo vital: nossa realidade em pesquisa. São Paulo: Casa do Psicólogo.

Costa, N. R. A. (2005). Construção de sentidos relacionados à maternidade è paternidade em uma família adotiva (Tese de doutorado não-publicada). Faculdade de Filosofia, Ciências e Letras de Ribeirão Preto, Universidade de São Paulo.

Costa, N. R. A., \& Rossetti-Ferreira, M. C. (2007). Tornar-se pai e mãe em um processo de adoção tardia. Psicologia: Reflexão e Crítica, 20(3), 425-434. 
Cúneo, L. A., Pella, M. E. B., Castiñeira, E., Márquez, A. F., Felbarg, D., \& Muchenik, J. (2007). Relaciones fraternas en la adopción. Archivos Argentinos de Pediatría, 105(1), 74-76.

Diniz, J. S. (1993). Este meu filho que eu não tive. Porto: Afrontamento

Ebrahim, S. G. (2001). Adoção tardia: altruísmo, maturidade e estabilidade emocional. Psicologia: Reflexão e Crítica, 14 (1), 73-80.

Ghesti-Galvão, I. (2008). Intervenções psicossociais e jurídicas no percurso da adoção: a mediação entre o afeto e a lei (Tese de doutorado não-publicada). Programa de Doutorado em Psicologia Clínica e Cultura. Universidade de Brasília.

Gomes, K. P. S. (2006). A adoção à luz da teoria winnicottiana. Winnicott e-prints, 1, 1-33.

Gomes, I. C., \& lyama, R. (2001). Atendimento breve de orientação psicanalítica a pais de crianças adotivas. Boletim de Psicologia, 114(51), 109-121.

Hernandez, J. A., \& Hutz, C. S. (2009). Transição para a parentalidade: ajustamento conjugal e emocional. Psico, 40(4), 414-421.

lyama, R., \& Gomes, I. C. (2005). A adoção sob um "olhar" winnicottiano. Encontro: Revista de Psicologia, 10(12), 58-70.

Levinzon, G. K. (2004). Adoção. São Paulo: Casa do Psicólogo.

Levy, L., \& Féres-Carneiro, T. (2001). Da maternidade impossível ao possível da filiação: sobre o desejo de adoção. Tempo Psicanalítico, 33, 77-87.

Mariano, F. N., \& Rossetti-Ferreira, M. C. (2008). Que perfil da família biológica e adotante, e da criança adotada revelam os processos judiciais? Psicologia: Reflexão e Crítica, 21(1), 11-19.

Otuka, L. K. (2009). Adoção por famílias com filhos biológicos: a perspectiva dos casais adotantes (Monografia não-publicada). Faculdade de Filosofia, Ciências e Letras de Ribeirão Preto, Universidade de São Paulo.

Otuka, L. K., Scorsolini-Comin, F., \& Santos, M. A. (2009). A configuração dos vínculos na adoção: uma atualização no contexto latino-americano. RevistaBrasileira de Crescimento e Desenvolvimento Humano, 19(3), 475-486.

Otuka, L. K., Scorsolini-Comin, F., \& Santos, M. A. (2010). O entrelaçamento dos desejos no projeto de adoção por famílias com filhos biológicos: uma compreensão winnicottiana. Revista da Sociedade de Psicologia do Rio Grande do Sul, 9(1), 155-167.

Otuka, L. K., Scorsolini-Comin, F., \& Santos, M. A. (2012). Adoção suficientemente boa: experiência de um casal com filhos biológicos. Psicologia: Teoria e Pesquisa, 28 (1), 55-63.
Pereira, J. M. F., \& Santos, M. A. (1998). O enfoque psicológico da adoção: revisão da literatura. In R. C. Labate (Org.), Caminhando para a assistência integral (pp.225-247). Ribeirão Preto: Scala.

Peres, R. S., \& Santos, M. A. (2005). Considerações gerais e orientações práticas acerca do emprego de estudos de caso na pesquisa científica em Psicologia. Interações, 20(10), 109-126.

Rosa, D. B. (2008). A narratividade da experiência adotiva: fantasias que envolvem a adoção. Psicologia Clínica, 20 (1), 97-110.

Santos, M. A., Raspantini, R. L., Silva, L. A. M., \& Escrivão, M. V. (2003). Dos laços de sangue aos laços de ternura: o processo de construção da parentalidade nos pais adotivos. Psic, 4(1), 14-21.

Sarti, C. A. (1996). A família como espelho. Campinas: Autores Associados.

Schettini, S. S. M., Amazonas, M. C. L. A., \& Dias, C. M. S. B. (2006). Famílias adotivas: identidade e diferença. Psicologia em Estudo, 11(2), 285-293.

Scorsolini-Comin, F., \& Santos, M. A. (2008). Aprender a viver é o viver mesmo: o aprendizado a partir do outro em um grupo de pais candidatos à adoção. Vínculo, 5(2), 115-130.

Sólon, L. A. G. (2009). Conversando com crianças sobre adoção. São Paulo: Casa do Psicólogo.

Triviños, A. N. S. (1987). Introdução à pesquisa em ciências sociais: a pesquisa qualitativa em educação. São Paulo: Atlas.

Uziel, A. P. (2007). Homossexualidadee adoção. Rio de Janeiro: Garamond.

Vargas, M. M. (1998). Adoção tardia: da família sonhada à família possível. São Paulo: Casa do Psicólogo.

Winnicott, D. W. (1993). Psicose e cuidados maternos. In D. W. Winnicott. Textos selecionados: da pediatria à psicanálise (pp.491-498). Rio de Janeiro: Francisco Alves. (Originalmente publicado em 1945).

Winnicott, D. W. (1997a). Duas crianças adotadas. In D. W. Winnicott. Pensando sobre crianças (pp.115-125). São Paulo: Artmed. (Originalmente publicado em 1953).

Winnicott, D. W. (1997b). A família e o desenvolvimento individual. São Paulo: Martins Fontes. (Originalmente publicado em 1965).

Recebido em: 23/5/2011

Versão final em: 20/3/2012

Aprovado em: 10/4/2012 
